\title{
Infância, loucura e alteridade:^ a criança em devir
}

\author{
Magda Medianeira de Mello ${ }^{\text {Orcid, I, } \star \star ~ J a n a i n a ~ D o r i g o ~ d o s ~ S a n t o s ~}{ }^{\text {Orcid, II }}$ \\ ${ }^{I}$ UNICNEC - Centro Universitário Cenecista de Osório, Osório, RS, Brasil \\ II Centro Universitário da Serra Gaúcha, Caxias do Sul, RS, Brasil

\section{Resumo}

$O$ artigo tem como objetivo investigar a infância que é vivenciada por crianças em um Centro de Atenção Psicossocial infantojuvenil - CAPSIJ, a partir da análise dos registros de uma experiência de estágio. Para tal, a metodologia utilizada foi o estudo de caso de um CAPSIJ. Traçando um retrato do CAPSij, foi possível evidenciar como se articula o serviço para propor intervenções com as crianças ali atendidas. Por meio da análise do relato das atividades desenvolvidas no local, do fluxo do serviço e do registro das interações com a equipe do local, percebeu-se um modo de cuidado peculiar e em constante construção, possibilitando formas de construção de subjetividade, bem como de apropriação de si mesmo. Diante do exposto no estudo de caso, foi possível concluir que há possibilidades de alteridade para a criança que frequenta o CAPSij desde que considerada a escuta e o devircriança de cada profissional que atua serviço.

Palavras-chave: alteridade; criança; infância; loucura.

\section{Childhood, madness and otherness: the child in becoming}

\section{Abstract}

The article aims to investigate how childhood is experienced by children in a psychosocial care center for children and adolescents - CAPSij, starting at one internship experience. For this, the methodology used was the CAPSij's case study with the exploratory type method. Drawing a portrait of CAPSij, it was possible to show how the service is structured to propose interventions with children who attend it. Through the activities, the flow of the service and interactions with facility staff noticed a peculiar way of care and under constant construction enabling forms of construction of subjectivity, as well as appropriation of itself. Given the above in the case study and literature survey, it was concluded that there are possibilities of alterity for the child who attends CAPSij since considered the listening and the becoming-child of each professional who works in the service.

Keywords: alterity; children; childhood; insanity.

\section{Introdução}

A reforma psiquiátrica brasileira marca a ruptura da assistência às pessoas com sofrimento psíquico através do modelo hospitalocêntrico, na redução sistemática de leitos psiquiátricos e na substituição dos cuidados, para um atendimento humanizado na rede extra-hospitalar. Foi pelos movimentos sociais e políticos protagonizados por usuários, trabalhadores e familiares que se construiu o espaço para a Política de Saúde Mental e implementação de serviços substitutivos na rede de saúde. Entre os serviços, os Centros de Atenção Psicossocial (CAPS) contribuem para o atendimento articulado à rede de saúde, com integralidade de ações e de modo territorial, buscando o cuidado substitutivo à internação e não apenas complementar. O CAPS Infanto-Juvenil, como um serviço especializado, direcionado às crianças e adolescentes com sofrimento psíquico e necessidades de cuidado de uma equipe de saúde, previne possíveis internações e serve de palco para instituir a infância tutelada pelo Estado.

O fortalecimento e promoção da reinserção social de crianças, através dos atendimentos no CAPSij, torna-se um processo contínuo e diverso ao construir formas de cuidados para além do modelo fechado e fragmentado. A infância que permeia o CAPSij possui características

\footnotetext{
$\star$ De acordo com o Dicionário de Filosofia de Abbagnano (2007, p. 35), o termo alteridade significa "ser outro, pôr-se ou constituir-se como outro". Assim sendo, alteridade é a habilidade de nos colocarmos no lugar do outro nas relações interpessoais.

$\star \star$ Endereço para correspondência: UNICNEC - Centro Universitário Cenecista de Osório/RS R. Vinte e Quatro de Maio, 141 - Centro, Osório - RS, 95520 000.E-mail:magdamello23@gmail.com, janadorigo@gmail.com
}

e dimensões peculiares, advindos das formas de encaminhamentos, atravessamentos sociais, de saúde e históricos familiares. No entanto, cabe ao CAPSij a propensão de possibilidades de alteridade e construção de autonomia à infância que se apresenta, para esta não ficar enquadrada somente nos muros deste serviço e ao que é destinado a ela.

O entendimento de que as crianças são sujeitos de direitos e responsabilidades requer que se reavaliem constantemente as intervenções da rede de cuidado, que busca a proteção da infância, sob o prisma do Estatuto da Criança e do Adolescente (ECA), possuindo, assim, o constante atravessamento judicial na rede de cuidado da infância. O CAPSij articula mudanças de paradigmas na assistência às crianças que frequentam o serviço, obedecendo diretrizes da Reforma Psiquiátrica e ampliando o campo de cuidado de forma intersetorial. Deste modo, cabe questionar que alteridade há para a criança que existe na infância habitada pela loucura?

O motivo que leva este trabalho a abordar a infância, a loucura e a alteridade é um questionamento profundo acerca das práticas de cuidado e proteção destinadas a este público. Como, por exemplo, o Centro de Atenção Psicossocial, serviço de saúde que pretende oferecer um serviço humanizado e substitutivo às internações psiquiátricas de crianças e adolescentes. Entretanto, questionar temas relacionados à infância já era de interesse de uma das pesquisadoras, visto que o seu local de trabalho como educadora social é propício ao surgimento de dúvidas, perguntas e interesses sobre o mundo infantil. 
Um mundo que encanta e que produz incógnitas às ações feitas para preservar os direitos fundamentais das crianças, estimulando, assim, a busca por respostas.

Em um mergulho no universo da infância institucionalizada e em inúmeros atravessamentos, foi possível formular algumas questões: quando a criança é um sujeito com voz, direitos e autonomia? Na sociedade em que habitamos há lugar para o protagonismo infantil? Quando é perguntado às crianças que estão sob a proteção do Estado o que elas querem e o de que precisam? Quem pensa e como pensa as possibilidades para as crianças que não têm lugar de discurso na sociedade contemporânea? Questionamentos sobre crianças que vivem à margem de seus direitos básicos relativos à vida, à liberdade e à vivência em família e em comunidade. Questionamentos que necessitam não apenas de respostas de um segmento das redes de atenção às crianças e aos adolescentes do serviço público, mas de um olhar múltiplo e não fragmentado.

No terreno da Assistência Social, pôde-se construir um caminho de dúvidas, busca de respostas e construção de experiências com a infância, conhecendo uma psicologia para além da teoria, tendo os primeiros contatos práticos com a psicologia social e produzindo novas perspectivas relativas à futura profissão. A pesquisa possibilitou um aprofundamento em temas da área social, no encontro da psicologia e das políticas públicas, nas aproximações com a saúde mental e coletiva e nas experiências em equipes interdisciplinares.

\section{Fundamentação Teórica}

Questionar que possibilidades há para a criança habitada pela loucura é abrir espaço para se pensar as redes históricas que contribuíram para a construção dos conceitos de infância e loucura. Sendo assim, há a necessidade de tal questionamento para, posteriormente, pensar-se sobre as possibilidades de alteridade dadas às crianças consideradas "loucas".

\section{Infâncias}

A infância da atualidade é produto de um legado histórico, atravessado por questões sociais, econômicas, culturais e religiosas. Contudo, é necessário evidenciar que, antes de tais atravessamentos, a infância é fruto do olhar do adulto sobre a criança, proporcionando uma suposição de necessidades das crianças e práticas de cuidado direcionadas a elas. Larrosa (1998, p. 68) expõe a existência de uma perspectiva do adulto sobre a criança ao escrever que "a infância é algo que nossos saberes, nossas práticas e nossas instituições já capturaram: algo que podemos explicar e nomear, algo sobre o qual podemos intervir, algo que podemos acolher".

Além do olhar direcionado e do legado histórico, pode-se compreender que a infância é um conceito construído conforme o contexto em que nasce, gerando, assim, múltiplas infâncias e, consequentemente, diversas formas de cuidado. Lemos (2014, p. 28) contempla essa diversidade emergente ao dizer que "algumas infâncias são mais punidas do que outras, algumas são menos

Fractal, Rev. Psicol., v. 30 - n. 3, p. 314-321, 2018 protegidas do que outras, ou seja, a balança da justiça tem cor, lugar, grupo, escolaridade, etnia, raça, gênero e configuração familiar".

As primeiras diferenciações de criança e adulto ocorreram no século XVI, pela idade cronológica, sem ainda existir a construção do conceito infância. Varela e Alvarez-Uria (1992, p. 71) citam características que eram atribuídas nesse período a quem ainda não havia chegado à idade adulta:

[...] maleabilidade, de onde se deriva sua capacidade de ser moldada, fragilidade (mais tarde imaturidade) que justifica sua tutela; rudeza, sendo então necessária sua 'civilização'; fraqueza de juízo, que exige desenvolver a razão; qualidade da alma, que distingue o homem dos animais; e, enfim, natureza em que se assentam os germes dos vícios e das virtudes [...].

Entende-se, a partir das características acima, que o período do desenvolvimento que contempla a criança existia para que a mesma fosse moldada aos bons costumes da época e doutrinada para determinada religião.

A família burguesa surge e divide a tutela das crianças com o colégio, ao mesmo tempo em que as instituições de caridade assumem o papel da tutela com as famílias pobres, gerando uma notável separação por classe social. É nesse período que se inicia uma diferenciação da infância rica e da infância pobre, denunciando as influências classistas e econômicas.

A infância "rica" vai ser certamente governada, mas sua submissão à autoridade pedagógica e aos regulamentos constitui um passo para assumir "melhor", mais tarde, funções do governo. A infância pobre, pelo contrário, não receberá tantas atenções, sendo o hospital, os hospícios e outros espaços de correção os primeiros centros pilotos destinados a moldá-la (VARELA; ALVAREZ-URIA, 1992).

Até o século XIX existem apenas perspectivas, a partir do olhar atual, do que poderia ser considerada infância naquela época. $\mathrm{O}$ vislumbre da infância surge com os primórdios do sentido de família, oriundo da família burguesa e da eclosão da escola. A escola nasce para ser um lugar de domesticação e passagem para a vida adulta, fazendo com que a infância seja um período de 'retiro' da sociedade. Dessa forma, a criança passa a ser submetida a métodos de modelamento de comportamento e transmissão de conhecimento, sendo formada como um sujeito pronto para a vida adulta.

A criança foi separada dos adultos e mantida à distância, numa espécie de quarentena, antes de ser solta no mundo. Esta quarentena foi a escola, o colégio. Começou então um longo processo de reclusão das crianças (como dos loucos, dos pobres e das prostitutas), que se estenderia até os nossos dias e ao qual se dá o nome de escolarização (VARELA; ALVAREZ-URIA, 1992, p. 96).

O século XX foi palco da reprodução do olhar histórico colocado na criança, ampliando espaços para a sua normatização em massa nas escolas. A escola como lugar para depositar as crianças, sem considerá-las sujeitos de potência para a constituição de sujeito crítico, mas como fase da vida que merece investimentos de 
controle, proteção e modelamento para uma futura vida adulta enquadrada ao padrão vigente. Cria-se a visão contemporânea de que tudo é possível ser feito, ou pelo menos quase tudo, para que suscitem benefícios para a criança, tendo em vista que os benefícios para a criança se deduzem a partir do olhar do adulto sobre ela.

Marino (2013, p. 2) salienta que "a etimologia da palavra infância vem de infans, que significa aquele que não fala, isto é, aquele que se distingue do adulto pela não apropriação da fala". Essa definição sublinha o lugar dado à criança nas infâncias existentes, um lugar sem voz, por isso sem direitos, sem vontades, sem curiosidades, sem desejo. E, se não é aberto espaço para fala, tampouco para a escuta da real demanda da criança. Fuganti (2008, p. 67) contribui quando fala que o conceito de criança tem a função de "conduzi-la ao status de homem com vontade livre e senso de responsabilidade pelos seus atos, sem perder de vista o atributo que lhe foi fixado e ao qual está predestinado". Para a criança rica há um caminho determinado conforme sua condição social, e para a criança pobre há um caminho sob o discurso da vulnerabilidade social e sob o olhar tutelar do Estado. O olhar dado à criança pobre fortalece a lógica da proteção, contribuindo para uma dupla tutela: do transtorno mental e da vulnerabilidade social.

\section{Vulnerabilidade: um ponto em comum entre uma infância e o CAPSij}

Pensar a infância sob a ótica atual é pensar nas novas formas de cuidado que se tem com essa população. As formas de cuidado contemporâneas são formas que controlam, vigiam, mas não mais enclausuram como ocorria na sociedade disciplinar. $\mathrm{Na}$ sociedade de controle, um novo dispositivo é o cidadão-polícia, que se dedica ao controle de si e do outro, termo esse que Passeti (2013, p. 161) conceitua quando escreve que "estamos em um momento de configuração desse sujeito polícia. $\mathrm{E}$, além disso, ele também funciona, de uma maneira consensual, como denunciante e como sujeito que produz o governo das condutas".

A vulnerabilidade é um dos elos entre a infância e o CAPSij, mas o que é vulnerabilidade? O que torna uma criança vulnerável e outra não? Para chegar a tais respostas compreende-se primeiramente que a vulnerabilidade social faz parte de uma construção social, com raízes profundas em questões que permeiam a sociedade capitalista atual. É certo que vários fatores considerados de risco são necessários para determinar a vulnerabilidade. Zavaschi (2009, p. 25) salienta em seu artigo "Crianças Vulneráveis" alguns fatores de risco como "vulnerabilidade neurológica, perdas por baixas condições socioeconômicas, morte ou separação dos pais, traumas por exposição à violência e traumas por abuso sexual".

Todavia, elencar uma série de características para considerar se uma criança é vulnerável ou não é caminhar em uma linha tênue de determinações e certezas absolutas em que o ato de prever, através de características de vulnerabilidade, não protege os direitos fundamentais da criança, mas sim tenciona a segregação por classes, ${ }^{1}$ como existente na psiquiatrização da loucura. Evidencia-se, então, que uma característica da vulnerabilidade sobressai sobre as demais: a questão econômica. As demais características de vulnerabilidade ocorrem em todas as classes sociais, mas não é em todas elas que o Estado intervém e que a família é dissecada e exposta. Cervo e Silva (2009, p. 2) complementam ao escrever que:

No contexto atual vemos crianças e adolescentes com trajetórias de exclusão, onde a escola lhes atribui rótulos, as famílias são tidas como desestruturadas, fugindo do modelo de família normatizada, possuindo péssimas condições de moradia, caracterizando um problema social 'digno' de intervenção, o que justifica algumas intervenções.

A vulnerabilidade é um ponto fundamental para uma criança ser encaminhada ao CAPSij, no entanto não é o único. Concomitantemente a esse requisito, é endereçada à criança que frequenta esse serviço um transtorno mental. "A entrada da criança no universo médico-psiquiátrico não deu-se [sic] pela loucura, mas por meio da etiologia de doenças mentais, pelos sinais de um desenvolvimento hipoteticamente comprometido", como consequência das percepções "da época acerca da hereditariedade da loucura” (MARINO, 2013, p. 3). No entanto, nem todas as crianças que possuem sofrimento psíquico e são atendidas pela rede pública de saúde são encaminhadas ao CAPSij.

Tal encaminhamento é destinado a pacientes que não se beneficiam com os atendimentos individuais e focais dos ambulatórios ou dos postos de saúde. Além disso, são pacientes que, em sua maioria, possuem históricos de violações de direitos, como agressões físicas, sexuais e negligência, e com vínculos familiares fragilizados ou rompidos, colocando em risco os direitos básicos das crianças e adolescentes. Zavaschi (2009, p. 4344) complementa ao evidenciar que muitas crianças encaminhadas ao atendimento no CAPSij "foram maltratadas física e emocionalmente; muitas sofreram abuso sexual, foram expostas à violência familiar, ao uso de drogas ou a doenças sexualmente transmissíveis". Muitas residem "nas ruas, se prostituem e cometem delitos como pequenos furtos, roubos e vandalismo".

\section{CAPSij: a construção do lugar (ou do caminho) para uma infância}

O CAPSij surge no Brasil como um serviço substitutivo às internações psiquiátricas de crianças e jovens até 18 anos de idade, sendo fruto da Luta Antimanicomial e resultado da Reforma Psiquiátrica. Um local com atravessamentos históricos e culturais que contrastam com as novas perspectivas de trabalho, em que alguns profissionais trazem na bagagem uma lógica anterior à nova proposta e outros profissionais possuem diferentes perspectivas de como trabalhar com os usuários do serviço.

\footnotetext{
${ }^{1}$ Afinal, o filho de um médico, pai negligente, que sofre durante anos violência psicológica e física por parte da madrasta e tem um final trágico, é menos vulnerável que uma criança que também sofre tais violências e acaba sendo encaminhada a uma casa de acolhimento institucional do Estado?
} 
No decorrer da história, percebe-se que as práticas higienistas surgiram no Brasil Imperial, mas somente no século XIX foi construído o primeiro hospital psiquiátrico em terras brasileiras. Essa época marca o despertar de uma atmosfera impregnada pelo saber científico psiquiátrico, no qual a psiquiatria foi elevada ao patamar de ciência ao transformar a loucura em doença mental. Ou seja, a loucura tornou-se objeto do saber psiquiátrico, adquirindo a denominação de transtorno mental; além disso, a psiquiatrização contribuiu para a manutenção da exclusão social. "A verdadeira força da sustentação exercida pelo manicômio não estava em produzir resultados terapêuticos, mas de exclusão social, de exclusão física, bem como de exclusão em relação ao universo de cidadania" (CONSELHO FEDERAL DE PSICOLOGIA [CFP], 2013, p. 55).

Nota-se que a tutela do Estado rege a infância e a loucura. A tutela da loucura é herança da Ditadura Militar, um período marcado por retrocessos em vários segmentos da sociedade. "Do ponto de vista da assistência psiquiátrica, a grande herança desse período é a privatização dos serviços com características clientelistas e a construção da chamada indústria da loucura" (CFP, 2013, p. 53). Salienta-se, então, um ciclo que se forma pela higienização social, a institucionalização da loucura e a produção de medicalização em massa.

Conforme aponta o Conselho Federal de Psicologia (2013, p. 63), "a Reforma Psiquiátrica brasileira tem antecedentes históricos distantes e múltiplos que estão ao mesmo tempo vinculados a movimentos sociais, experiências de assistência e transformação de marcos teórico e conceitual relativo ao campo". Dentro do processo histórico, o manicômio corresponde à sociedade disciplinar e o CAPSij surge na passagem do modelo de sociedade disciplinar para o modelo de sociedade de controle. "Vivemos em uma sociedade de controle que não se pauta mais na predominância da vigilância, do panóptico que vigia para punir e normatizar condutas. Estamos agora em um outro momento, o do monitoramento" (PASSETI, 2013, p. 165). Entretanto, há uma transição em processo e a necessidade de que ocorra uma constante transformação no CAPSij, para que esse não corresponda à sociedade de controle, bem como não retroceda à lógica manicomial.

Neste espaço de transição é que se encontram possibilidades de alteridade. Tal conceito denota o reconhecimento da diferenciação e separação de um sujeito e outro. Para a psicanálise, as primeiras experiências de alteridade acontecem ainda com o bebê que, através do olhar da mãe, reconhece que há outro além dele mesmo. "O olhar materno reassegura a existência dele [bebê]. A capacidade de ver e capturar o rosto do Outro é precedida pela possibilidade de ser capturado pelo Outro" (QUEIROZ, 2007, p. 32). Nas ciências antropológicas o termo alteridade é utilizado como forma de diferenciar as singularidades existentes nos campos de pesquisa, bem como diferenciar o pesquisador do

Fractal, Rev. Psicol., v. 30 - n. 3, p. 314-321, 2018 pesquisado. "Podemos dizer que a alteridade implica reconhecer a diferença em diferentes níveis e realidade" (RIBEIRO, 2006, p. 98).

Abordar o conceito de alteridade no espaço do CAPSij é aproximar-se do que preconiza esse serviço substitutivo: um espaço para o acolhimento de subjetividades e não apenas tratamento de doenças. E neste espaço só é possível o cuidado humanizado se o serviço não reproduzir práticas que formatem sujeitos, mas sim deem espaço para a construção da singularidade.

Sendo assim, as pesquisadoras buscam, neste estudo, investigar que alteridade há para a criança habitada pela loucura.

\section{Metodologia}

A pesquisa teve como objetivo investigar a infância que é vivenciada em um CAPSij específico. A metodologia utilizada para investigar o tema da "Infância, loucura e alteridade: a criança em devir" foi um estudo de caso que utilizou como fonte de coleta de dados registros documentais do material produzido durante o período de estágio nesse CAPSij. Junto a este material, também se contemplou a coleta de dados por meio do levantamento bibliográfico, considerando a legislação pertinente ao tema deste artigo.

O estudo de caso utilizou-se da abordagem de "[...] investigação de um fenômeno contemporâneo dentro do seu contexto real, onde os limites entre o fenômeno e o contexto não são claramente percebidos" (YIN apud GIL, 2010, p. 27). Trata-se, ainda, de uma pesquisa exploratória, por "proporcionar maior familiaridade com o problema, com vistas a torná-lo mais explícito" (GIL, 2010, p. 27), provendo maior conhecimento sobre o tema.

\section{$O$ retrato de um CAPSij}

O CAPSij no qual se fez o estudo de caso iniciou suas atividades em 2006 e localiza-se em um bairro de Caxias do Sul, no Rio grande do Sul, em uma casa residencial alugada, cujos cômodos são utilizados como salas e espaços para oficinas, reuniões e vivências com os usuários. Como espaço físico, o serviço possui salas de atendimentos individuais e grupais; espaço de convivência e de recreação; espaço para oficinas; pátio, cozinha, refeitório, recepção, banheiros e sala de equipe.

Inicialmente o serviço recebia os usuários por encaminhamentos dos serviços de saúde mental e dos órgãos de proteção. Contudo, alguns meses após a inauguração, passou a receber encaminhamentos também das UBS's. Atualmente, o acesso do usuário ao serviço é feito pela Rede Hospitalar, Cais mental, PA 24 horas, UBS's e Órgãos de Proteção a Crianças e Adolescentes. Desde o início, o serviço é contemplado por equipe interdisciplinar que, além das reuniões semanais, realiza movimentos intersetoriais formal e informalmente, para continuidade de decisões em contratos terapêuticos.

O CAPSij tem capacidade de atendimento para 155 usuários, sendo 25 para atendimento intensivo, 50 para atendimento semi-intensivo e 80 para atendimento não intensivo. A intensidade de atendimento depende do 
grau de gravidade do sofrimento psíquico da criança ou adolescente e das possibilidades do serviço e da família. Atualmente o CAPSij atende 120 usuários.

Considerando os relatos documentais do estágio curricular no serviço, é possível compreender uma construção diária de um modelo de atenção antimanicomial. Isso porque há um movimento intersetorial e multiprofissional dos profissionais, proporcionando modos de atendimento que buscam a conformidade com a Reforma Psiquiátrica, contribuindo para uma constante maleabilidade no serviço, o que o torna dinâmico e proporciona o enfoque do trabalho no usuário.

[...] é preciso lembrar que, como processo em curso, a prática dos CAPS e a ética libertária da reforma psiquiátrica convivem e se defrontam, cotidianamente, com os mitos da incapacidade, periculosidade, com os mandatos de tutela e exclusão, ou seja, com a lógica manicomial que interpela a Reforma Psiquiátrica e os CAPS na validade de sua resposta, mesmo frente à sensível inovação de sua prática e seus efeitos transformadores (CFP, 2013, p. 99).

$\mathrm{O}$ acesso ao serviço ocorre, na maioria das vezes, por contato telefônico em que é feita uma triagem telefônica. Uma ficha de dados é preenchida com informações básicas do usuário. É agendado o acolhimento, que é feito por uma dupla de profissionais com atendimentos separados da criança e do responsável, para que sejam ouvidas as demandas dos dois lados. "Escutar significa, num primeiro momento, acolher toda a queixa ou relato do usuário mesmo quando possa parecer não interessar diretamente para o diagnóstico e tratamento" (BRASIL, 2008, p. 16). O critério para que seja feito o acolhimento é o profissional ter graduação em alguma área; sendo assim, os profissionais de ensino superior se revezam semanalmente para os acolhimentos marcados.

Após o acolhimento, é marcada a consulta para avaliação psiquiátrica da criança ou adolescente encaminhado. Na segunda-feira seguinte à consulta psiquiátrica, na reunião de equipe, discute-se o caso para verificar se é para os atendimentos do CAPSij ou para outro serviço. Caso seja um novo usuário do CAPSij, discute-se o PTS (Plano Terapêutico Singular). "O PTS é um conjunto de propostas de condutas terapêuticas articuladas, para um sujeito individual ou coletivo, resultado da discussão coletiva de uma equipe interdisciplinar" (BRASIL, 2008, p. 40).

Cada usuário possui um profissional de referência. No CAPSij especificamente, os profissionais acabam sendo referência do usuário que fez o acolhimento. Não há necessidade de um profissional realizar alguma oficina ou atividade com o usuário a qual é referência, mas toda informação que surgir no serviço é passada para o profissional responsável. "As equipes de referência são uma forma de resgatar o compromisso com o sujeito, reconhecendo toda a complexidade do seu adoecer e do seu projeto terapêutico" (BRASIL, 2008, p. 39).

Semanalmente, ocorrem duas reuniões de equipe em que todos contribuem com falas na discussão. "Reunião é um espaço de diálogo e é preciso que haja um clima em que todos tenham direito à voz e à opinião" (BRASIL, 2008, p. 53). Em um dos dias da semana há o estudo de caso e discussão dos PTS. "Cada membro da equipe, a partir dos vínculos que construiu, trará para a reunião aspectos diferentes e poderá também receber tarefas diferentes, de acordo com a intensidade e qualidade desse vínculo" (BRASIL, 2008, p. 42). Neste mesmo dia, uma vez por mês, ocorre o 'cuidado ao cuidador', em que um profissional é responsável por fazer uma atividade direcionada à equipe, promovendo a saúde desta. Em outro dia da semana, uma segunda reunião é direcionada à programação da semana que está por vir, para a participação dos profissionais em atividades que ocorrem na cidade, nos serviços de saúde e no próprio CAPSij. Também é feito um feedback do que ocorreu na última semana.

Enquanto ocorrem os atendimentos no CAPSij, a equipe promove articulações com a rede (Ministério Público, Conselho Tutelar, Delegacia da Criança e do Adolescente, Serviços de Saúde, Serviços Educacionais, Serviços da Assistencial Social) para a continuidade e necessárias atualizações do PTS. "Estar em rede também é estar em movimento. Nenhum dos dispositivos ou pontos de cuidado funciona fechado em si mesmo, e aumentam sua potência quando se articulam em rede" (CFP, 2013, p. 103). É perceptível uma constante luta para estabelecer na rede, não só o lugar físico do CAPSij, mas também a permanência da lógica do serviço, que entende que há possibilidades de tratamento dos usuários, sem o enclausuramento na rede hospitalar. A rede de atenção à saúde, bem como outros serviços da rede intersetorial, muitas vezes tencionam o encaminhamento para internação psiquiátrica; assim, cabe ao CAPSij a construção de uma prática para além da institucionalização hospitalar da infância e de adolescência.

Desinstitucionalizar a prática implica em abandonar o manicômio como causa, como sentido lógico que prescreve modos de vida limitados, anônimos e sem voz. E para isso não há manual ou código de conduta, mas há uma ética. A ética da liberdade. E há saber. Saber que quase nada se sabe e que o outro, o louco, pode e deve nos orientar quanto às possibilidades de saída para sua dor (CFP, 2013, p. 102).

O desligamento do serviço pelo usuário pode ocorrer pelos seguintes motivos: sem perfil para atendimento; alta médica; transferência para outro município; evasão e idade em que pode ser encaminhado para o Ambulatório Especializado em Saúde ou para o CAPS II da cidade. O serviço enfrenta problemas por falta de adesão de alguns usuários, devido à dificuldade de acesso aos espaços de atendimento. Por levantamentos, percebeu-se que aproximadamente 60 por cento das famílias atendidas têm baixo poder aquisitivo e necessitam utilizar no mínimo dois ônibus para a chegada ao serviço, tornando as faltas aos atendimentos rotineiras. Para alguns casos em que as famílias não têm condições de locomoção, o CAPSij fornece passagem de transporte público para a ida aos atendimentos.

Fractal, Rev. Psicol., v. 30 - n. 3, p. 314-321, 2018 


\section{Apresentação dos resultados}

Esta pesquisa teve como objetivo investigar a infância vivenciada pelas crianças em um CAPSij. Cabe salientar que nos últimos 200 anos a psicopatologia, muito mais que uma ciência, faz parte da cultura social e é usada por definir quem são as pessoas e para nomear os sentimentos que emergem de cada um, demarcando o que é normalidade e a sua diferença e o que é merecedor de intervenção por encontrar-se numa zona patológica. Entretanto, é válido lembrar que as patologias existem conforme o contexto e algumas são específicas de determinadas culturas.

$\mathrm{Na}$ nossa cultura, somos assujeitados à moral, à legislação, à razão e ao Estado. Herança de Platão, que propõe que somos livres desde que submetidos a essas vigências (moral, lei, ordem, razão), para assim vivermos na civilização ocidental. Um assujeitamento naturalizado, pois é considerado correto. E é nesta nossa cultura que é perceptível que alguns comportamentos das crianças são considerados anormais, não por questões das crianças, mas por deficiência da sociedade em aceitar tais comportamentos. Uma deficiência que é múltipla e abrange vários segmentos, pois há deficiência da escola em ter apenas uma professora para quarenta alunos, que demandam atenção quanto aos seus questionamentos inquietantes e que mobilizam; deficiência do parquinho da praça, que não possui infraestrutura adequada para as crianças brincarem e, consequentemente, estas acabam brincando onde "não se deve"; deficiência da família, que têm pais que, adequados à norma econômica e social vigente, trabalham oito horas diárias, ou mais, estudam para acompanharem as evoluções do mercado de trabalho e não têm tempo para olharem seus filhos, e por aí vai. Em cada espaço há uma deficiência, que é mascarada ou não percebida quando se direciona uma "culpa" à criança, por não se adaptar aos enquadramentos sociais. Qual o procedimento para tudo isso? Encaminhar a criança para um acompanhamento especializado e assim enquadrá-la às normas sociais, em um padrão de criança mais eficiente, que se adapte melhor à correria da atualidade, afinal, "no contexto em que a infância é uma fase da vida, a criança tornou-se objeto privilegiado, já que tudo é possível desde que seja para o benefício dela" (MARINO, 2013, p. 3)

A partir disso, ressalta-se ser necessário não se limitar a este "fluxo" cheio de determinismos, que direciona as crianças a uma lapidação de sua subjetividade, levando-nos à atmosfera do clipe Another brick in the wall, da banda Pink Floyd (1979). Uma atmosfera em que as crianças evidenciam que não precisam daquela educação e daquele controle mental para se transformarem, pois a transformação determinada a elas é ser apenas mais um tijolo no muro.

A criança por si só não será apenas mais um tijolo no muro se for aceita como ela é e se for aceito aquilo no qual se tornará, dando-lhe o direito a ter sua história sem rótulos pré-dispostos. A criança possui em si possibilidades infinitas, pois está aberta a tudo. Fuganti (2008) evidencia esta característica da criança ao escrever que "a criança é pura potência de afetar e ser afetada. Ela está aberta às multiplicidades do mundo" (FUGANTI, 2008, p. 66). Assim, por si só a criança tem em si a alteridade. Ceccin e Palombini (2009, p. 308) contribuem quando conceituam que a criança "é um conjunto de potência devindo. A marca da criança é sua expressão por intensidades, sua aprendizagem pela experimentação e pelo jogo. A criança realiza o encontro real-imaginário".

A alteridade da infância é algo muito mais radical: nada mais e nada menos do que sua absoluta heterogeneidade no que diz respeito a nós e a nosso mundo, sua absoluta diferença. E se a presença enigmática da infância é a presença de algo radical e irredutivelmente outro, deverse-á pensá-la à medida que sempre nos escapa: à medida que inquieta o que sabemos (e a soberba de nossa vontade de saber), à medida que suspende o que podemos (e a arrogância da nossa vontade de poder) e à medida que coloca em questionamento os lugares que construímos para ela (e a presunção de nossa vontade de abarcá-la). Aí está a vertigem: na maneira como a alteridade da infância nos leva a uma região na qual não regem as medidas do nosso saber e do nosso poder (FUGANTI, 2008, p. 70).

Uma alteridade que não precisa ser construída para a criança pois é dela, fora do nosso alcance externo, uma alteridade que não exige controle, porto seguro ou um chão firme para pisar, que evidencia uma diferença entre crianças e adultos na qual "este prefere mapas que indicam os percursos a seguir, localiza onde está, decide onde quer chegar, compra o mapa com roteiros já delimitados e migra de um lugar para o outro" (CECCIN; PALOMBINI, 2009, p. 308). Para o devir-criança não há esses limites do mundo adulto, se o adulto permitir a erupção dessa potencialidade, não aprisionando nem excluindo as possibilidades.

"Mas em nossa sociedade a criança está, desde o nascimento, prisioneira do círculo papai-mamãe-édipo da família nuclear burguesa. A primeira doença que inocula na criança é o Édipo. Seu pecado original? Sentimentos parricidas e incestuosos" (FUGANTI, 2008, p. 66). Desde o nascimento da criança, já se atravessam limitações e, ao longo do seu crescimento, sofre intervenções com a justificativa do que é considerado melhor para ela, de que ainda não é capaz de cuidar de si, de falar por si. Realmente, de modo fisiológico e psíquico, o ser humano tem a necessidade de ser cuidado e protegido, caso contrário não sobreviveria. Mas em que momento o ser humano passa a ter voz e direito por ele mesmo enquanto é criança?

A criança se desenvolve e se constitui com as intervenções do social, das instituições, do que os pais acham que é bom e do que podem proporcionar; desenvolve-se recebendo rótulos e sendo estereotipada nas adaptações que sofre no meio. Mas, para além dessa criança, há um devir-criança que é:

a resistência a esses agenciamentos, e a criança sobrevém no adulto, sobressai-se em seus acessos de alegria, em sua curiosidade risonha, no bom-humor ou quando detecta uma nova suavidade nos encontros. Para um devir-criança, não existe o 'homem', a forma-homem, o que há é um movimento 
de dissolução das formas criadas (DELEUZE; GUATTARI, 1997, p. 19 apud CECCIN; PALOMBINI, 2009, p. 308).

Assim, para cuidar dessa criança, os adultos constroem lugares que por vezes as enclausuram a uma existência determinada pelo silêncio subjetivo. Brum (2014) nos traz o exemplo de sua pesquisa em um hospital psiquiátrico onde evidencia um fluxo perigoso de internações e encaminhamentos descompromissados de crianças que têm suas vidas esmagadas pelas paredes manicomiais e acabam rotuladas de crianças loucas. "Ao fazer o arquivo morto falar, Flávia constrói respostas que precisam ser escutadas se quisermos, de fato, estancar o crime de fabricar crianças loucas - e, muitas vezes, também o de conseguir enlouquecê-las" (BRUM, 2014, par. 14). E o que resta dentro desse sistema para essas crianças é viver uma adultez não muito diferente, sendo encaminhadas de instituição em instituição e não possuindo um lugar em meio a esses encaminhamentos.

Os serviços substitutivos, como o CAPSij, têm como princípio primordial a possibilidade de se transitar pelos espaços do local, não enclausurando as subjetividades que ali se encontram. Uma tarefa que não é simples para a equipe de profissionais do local, onde a práxis precisa ser repensada constantemente para que os profissionais não caiam na antiga lógica manicomial. Um serviço que deve propor o cuidado pela não exclusão de uma população que já tem em sua história a segregação social. "Para cuidar, será preciso derrubar todos os movimentos de exclusão da alteridade [...]. Será necessária a abertura aos encontros de afecção, será necessário encontrar-se com o outro. A exclusão da alteridade é a exclusão do cuidado" (CECCIN; PALOMBINI, 2009, p. 310).

Assim, mesmo repensando constantemente o cuidado dado às crianças que frequentam o local, para que se propicie a alteridade da criança, também é necessário dar abertura ao devir-criança que há nos profissionais que ali atuam, para assim alcançar uma sintonia com o público que frequenta o serviço. Tal sintonia significa afetar e se deixar ser afetado num partilhamento do encontro entre crianças e profissionais e do que emerge dele. Ceccin e Palombini (2009, p. 310) contribuem ao afirmarem que "a criança, em sua condição de vulnerabilidade e sensibilidade, deixase afetar pelo outro. Um devir-criança em nós asseguranos essa escuta ética do e pelo outro nas situações que envolvem cuidado e educação em ato".

$\mathrm{O}$ acesso da criança ao olhar do outro permite a constituição do seu ser. Larrosa (1998, p. 9) propõe que se inverta a direção do modo de olhar considerando a imagem do outro que nos olha e interpela, e não o contrário.

O outro, ao olhar-nos, põe-nos em questão, tanto o que nós somos como todas essas imagens que construímos para classificá-lo, para excluí-lo, para proteger-nos de sua presença incomoda, para enquadrá-lo em nossas instituições, para submetê-lo às nossas práticas e, finalmente, para fazê-los como nós, isto é, para reduzir o que pode ter de inquietante e ameaçador. A atenção ao modo de olhar do outro, pensávamos, talvez permita a emergência de outra forma do pensamento e, talvez, de outro tipo de prática social (LARROSA, 1998, p. 9).
Neste sentido, compreende-se que propiciar o encontro da criança e adulto em um ambiente onde há a escuta do profissional para aquela criança e suas demandas, inquietudes e curiosidades, permite a construção da alteridade, proporciona à criança a apropriação de si mesmo e o surgimento do sujeito singular que ali está. Talvez essa escuta seja um ponto fundamental para a construção das possibilidades de alteridade da criança que se encontra nos serviços oferecidos no CAPSij.

\section{Considerações Finais}

A investigação buscou apresentar a infância existente no CAPSij, acompanhando as propostas para, a partir delas, abrir a oportunidade de pensar as perspectivas de alteridade para as crianças que frequentam o serviço. A infância vivenciada no CAPSij é peculiar na medida em que a criança que a experiencia necessita de cuidados especiais e de espaço com alternativas para vivenciá-la. Uma infância que ainda não é aceita em todos os espaços sociais, tendo, assim, a possibilidade de ter ali um lugar seu. Que tem atravessamentos, relacionados a questões sociais e de saúde mental, dois fatores que são considerados relevantes para o encaminhamento ao serviço.

Há possibilidades de alteridade para esta infância neste CAPSij? Talvez sim. As possibilidades dependem do cuidado que se dá às crianças e são amparadas por meio dele. Tal cuidado pode se fazer presente nas atividades propostas às crianças, que são pensadas em cada Plano Terapêutico Individual e modificadas sempre que se ache necessário e relevante. Também se faz presente nos momentos em que a equipe olha para si e promove o autocuidado, bem como a construção conjunta de uma escuta qualificada e ética.

Todavia, entendendo que a alteridade se produz no encontro entre a criança e o trabalhador, há a necessidade de esclarecer que não há como responder com certeza a esta pergunta, pois depende do momento em que o serviço se encontra e dos múltiplos fatores que se atravessam para que a alteridade seja possível.

$\mathrm{O}$ trabalho proporcionou às pesquisadoras novas formas de se olhar para esta infância, bem como de se deixar ser visto por ela, produzindo-lhes constantes questionamentos referentes à sua posição profissional diante deste público. Os adultos que atuam no CAPSij permitem-se deixar serem questionados e interpelados pela criança que se encontra no serviço? Permitemse serem afetados pelo que emerge no encontro com a criança? Permitem-se mergulhar em um contexto sem roteiros para assim aflorar sua escuta para com a criança? Questionamentos que transformam o modo de cuidado dos pesquisadores, transformando também o que surge a partir do cuidado. O tema "Infância, loucura e alteridade: a criança em devir" transborda caminhos para a sua abordagem, oportunizando futuras pesquisas, bem como a continuidade deste trabalho.

Fractal, Rev. Psicol., v. 30 - n. 3, p. 314-321, 2018 


\section{Referências}

ABBAGNANO, N. Dicionário de Filosofia. São Paulo: Martins Fontes, 2007.

BRASIL. Ministério da Saúde. Secretaria de Atenção à Saúde. Política Nacional de Humanização da Atenção e Gestão do SUS. Clínica ampliada e compartilhada. Brasília: Ministério da Saúde, 2008.

BRUM, E. Como se fabricam crianças loucas. El País, 17 mar. 2014. Disponível em: https://brasil.elpais.com/ brasil/2014/03/17/opinion/1395072236 094434.html. Acesso em: 4 jul. 2014.

CECCIN, R. B.; PALOMBINI, A. L. Imagens da infância, devir-criança e uma formulação à educação do cuidado. Psicologia e Sociedade, Florianópolis, v. 21, n. 3, p. 301-312, set./dez. 2009. Cross ${ }^{\text {Ref }}$

CERVO, M. R.; SILVA, R. A. N. da. A produção de uma patologização da infância na experiência de um CAPSi. In: ENCONTRO NACIONAL DA ABRAPSO, 15, 2009, Maceió. Anais... Maceió: ABRAPSO, 2009. Disponível em: http://www.abrapso.org.br/siteprincipal/images/Anais XVENABRAPSO/481.\%20a\%20produ $\% \mathrm{C} 7 \% \mathrm{C} 3 \mathrm{o} \% 20$ de $\% 20$ uma $\% 20$ patologiza $\%$ C 7\% $\% 30 \% 20$ da $\% 20$ inf $\% \mathrm{C} 2$ ncia $\% 20$ na $\% 20$ experi $\%$ CAncia $\% 20$ do $\% 20$ capsi.pdf. Acesso em: 10 mar. 2014.

CONSELHO FEDERAL DE PSICOLOGIA. Referências Técnicas para Atuação de Psicólogas(os) no CAPS: Centro de Atenção Psicossocial/Conselho Federal de Psicologia. Brasília: CFP, 2013. Disponível em: https://site.cfp.org.br/ wp-content/uploads/2013/11/CAPS_05.07.pdf. Acesso em: 3 maio 2015.

FUGANTI, L. A. Saúde, desejo e pensamento. São Paulo: Hucitec/Linha de Fuga, 2008.

GIL, A. C. Como elaborar projetos de pesquisa. 5. ed. São Paulo: Atlas, 2010

LARROSA, J. O enigma da infância ou o que vai do impossível ao verdadeiro. In: Vozes, 1998. p. 67-86.

LEMOS, F. C. S. A judicialização da infância e seus impactos na vida das crianças e suas famílias. Desidades: Revista Eletrônica de Divulgação Científica da Infância e Juventude [online], ano 2, n. 2, p. 25-29, 2014. Entrevista concedida à Equipe Editorial da Revista DESidades. Disponível em: http://desidades.ufrj. br/open_space/entrevista-teste/. Acesso em: 8 abr. 2014.

MARINO,A.S.Acriançana interface do silêncio medicamentoso e como sujeito em psicanálise. Polêmica, v. 12, n. 1, jan./mar. 2013. Disponível em: http://www.e-publicacoes.uerj.br/ index.php/polemica/article/view/5274/3867. Acesso em: 10 mar. 2014

PASSETI, E. O carcereiro que há em nós. In: XIMENDES, A. M. C.; REIS, C.; OLIVEIRA, R. W. (Org.). Entre garantia de direitos e práticas libertárias. Porto Alegre: CRPRS, 2013. p. 147-181.

PINK FLOYD. Another brick in the wall. The Wall. London: Columbia/CBS Records, 1979. Disponível em: https://www. youtube.com/watch?v=YR5ApYxkU-U. Acesso em: 5 out. 2014.

Fractal, Rev. Psicol., v. 30 - n. 3, p. 314-321, 2018
QUEIROZ, E. F. de. A divisão do sujeito: a hipótese de uma Urverleugnung (desmentido primordial). Psychê (São Paulo), São Paulo, v. 11, n. 21, p. 47-62, jul./dez. 2007. Disponível em: http://pepsic.bvsalud.org/scielo.php?script=sci arttext\&pid=S1415-11382007000200004. Acesso em: 15 mar. 2014.

RIBEIRO, A. S. P. Teoria e prática em antropologia. Curitiba: Intersaberes, 2006.

VARELA, J.; ALVAREZ-URIA, F. A maquinaria escolar. Revista Teoria \& Educação, Porto Alegre, n. 6, p. 68-96, 1992.

ZAVASCHI, M. L. S. (Org.). Crianças Vulneráveis. In: Crianças e adolescentes vulneráveis: o atendimento interdisciplinar nos centros de atenção psicossocial. Porto Alegre: Artmed, 2009. p. 24-42.

Recebido em: 26 de julho de 2015 Aceito em: 27 de abril de 2018 